\title{
ПРОБЛЕМЫ ОЦЕНКИ КАЧЕСТВА НАЛОГОВОГО КОНСУЛЬТИРОВАНИЯ В УСЛОВИЯХ ЦИФРОВИЗАЦИИ В РОССИИ
}

\author{
(c) 2020 Князева Наталья Владимировна \\ доктор экономических наук, кандидат юридических наук \\ Генеральный директор НКО Ассоциация «Профессиональных судебных экспертов», Россия, Москва \\ E-mail: expert-knyazeva@mail.ru
}

(c) 2020 Павлова Ксения Сергеевна

кандидат экономических наук, доцент

Самарский государственный экономический университет, Россия, Самара

E-mail: mrs.pavlova@list.ru

Описаны различные подходы к получению компетенций, необходимых для работы налоговым консультантом. Обращено внимание на отсутствие прозрачного механизма выбора консультанта. Обозначена актуальность повышения цифровой ориентации специалистов и применения цифровых технологий в деятельности налоговых консультантов и экспертов. Указаны пробелы в регулировании контроля уровня профессиональных навыков налоговых экспертов и консультантов.

Ключевые слова: консультационные услуги, налоговый консультант, эксперт в области налогообложения, судебный налоговый эксперт, компетенция специалиста, оценка квалификации налогового консультанта

Проблеме качества налогового консультирования в практике уделяется большое внимание, благодаря развитию цифровизации экономических и социальных процессов, наличию колоссальной информированности у потребителей о поставщиках услуг в области налогового консультирования, применению консультантами персонифицированной информации о преимуществах своей деятельности на рынке услуг, связанных с вопросами налогообложения.

Клиент при потреблении консультации в области налогообложения ожидает получить комплексную качественную услугу, которая включает в себя не только ответы на поставленные вопросы клиента как налогоплательщика, но и указание на скрытые проблемы (например, недостатки в организации ведения налогового учета клиента или хранения документации, недостатки в полноте учета объекта налогообложения), возможности применения законных способов налоговой оптимизации. При этом уровень качества услуги клиентом изначально воспринимается и определяется участием специалиста определенной подтвержденной профессиональной компетенции в области налогообложения.

Согласно планам по реализации национальной программы «Цифровая экономика Российской Федерации», особую актуальность приоб- ретают направления по развитию цифровых технологий и по формированию информационной безопасности общества [1]. Внедрение элементов автоматизации процесса оказания услуг и использование в работе современных цифровых технологий становится объектом внимания в современном бизнес-сообществе, в частности в сфере налогообложения. Новый Премьер Министр РФ Михаил Мишустин утвердил свою репутацию технократа, на посту руководителя Федеральной налоговой службой РФ. В российских СМИ выражается мнение, что новое Правительство РФ будет более технократичным и направленным на реализацию национальных проектов.

Отметим, что 174 млн. налогоплательщиков используют для администрирования автоматизированную информационную систему ФНС России - АИС «Налог-3» в 2019 г. [2]. По данным ФНС России по телекоммуникационным каналам связи было принято 51 млн. налоговой и бухгалтерской отчетности; зарегистрировано 7 млн. обращений пользователей к электронным налоговым сервисам в 2019 г., которые размещены на официальном сайте ФНС России [2].

Важным условием в следовании современным тенденциям для налоговых консультантов становятся формирование дополнительных компетенций, связанных с цифровыми технологиями. К основным умениям специалистов 
в данном контексте следует относить: умение работать с базами данных на даталогическом уровне с навыками накопления, анализа, обработки и представления (datalogy-даталогия или data science - наука о данных), умение создавать информационную базу; умение сформулировать и представить последовательную цепочку блоков (связный список), содержащих информацию (англ. block chain - цепочка блоков), владение электронным документооборотом по налоговому и бухгалтерскому учетам на базе различных платформ, знание электронных сервисов ФНС, ведение электронных переговоров. Внедрение цифровых элементов анализа данных в налоговое консультирование позволит снизить время оказания услуг, что окажет позитивное влияние на лояльное отношение клиента к продуценту и поспособствует снижению ошибок, совершаемых по невнимательности, например при математических расчетах.

Налоговое консультирование - это прежде всего результат интеллектуального труда - мыслительного процесса опытного и компетентного специалиста, поэтому полностью автоматизировать процесс оказания услуги - не логично, и постановка такой задачи не целесообразна. Модель налогового консультирования может трансформироваться в формат дистанционной цифровой модели, которая позволит в режиме on-line отвечать на вопросы клиентов (экспрессконсультации), одновременно обобщать тематику актуальных вопросов и проблем, с целью включения в состав учебного и практического материала, которые можно использовать в проведении семинаров для собственных кадров, для сотрудников клиентов, а также для широкого круга заинтересованных лиц, например, в процессе обсуждения вопросов в профессиональном сообществе.

Очевидно, что обучение консультантов или слушателей целесообразно организовывать в электронной среде, используя для доступа слушателей к обучающему курсу личные кабинеты или единую электронную платформу. Такое обучение успешно реализуется в различных областях, в том числе при обучении налоговых консультантов в профессиональных сообществах.

Создание электронных сервисов, позволяющих общаться коллегам, решать проблемы клиентов в режиме «онлайн», необходимый вектор развития налогового консультирования. Режим позволяет более рационально распределить личное рабочее время каждого специалиста каждый участвует в обсуждении в удобное время и с должным вниманием.

Цифровизация экономического пространства, иными словами, вывело на новый уровень процесс оказания консультационных услуг и формирует направления развития. Однако, для контроля качества консультационной и экспертной услуги требуются инструменты, которые должны быть встроенными элементами регулирования деятельности как внутренними (внутри отрасли, компании, образовательного учреждения по подготовке специалистов), так и внешними (на уровне саморегулирования или законодательства).

Во-первых, при оказании консультационных услуг целесообразно иметь разработанные программы для каждого блока консультирования, которая позволит охватить все вопросы заданной области в определенной консультантом последовательности.

Во-вторых, консультирование должно иметь принятую политикой компании консультанта определенную степень защиты, позволяющую минимизировать или полностью исключить возможность недобросовестного поведения участников процесса, использование информации клиента для разглашения ее третьим лицам в незаконных или корыстных целях. Утечка данных о заказчике может иметь и непреднамеренных характер, если налоговый консультант не соблюдал в процессе работы правил информационной безопасности [3]. В целях защиты информации и сведений потребителя, его интересов как покупателя консультационных услуг требуется стандарт безопасности, который необходимо включить в требования к оказанию консультационных услуг. Стандартизация качества должна лежать в разумной плоскости, доступной для воплощения бизнесом, и минимальный набор требований должен быть установлен государством.

В-третьих, учитывая, что консультации в области налогообложения базируются на фундаментальном знании субъектом консультирования налогового права и экономического содержания деятельности, необходимо организовать двухуровневую систему контроля качества оказания консультационных услуг: как со стороны правового содержания, так и со стороны экономического характера консультационной услуги. В данном контексте стоит указать, 
что междисциплинарный характер образования налогового эксперта и налогового консультанта - непосредственного исполнителя услуги, должен быть включен в образовательный стандарт данных специалистов.

В любом случае при оказании услуг налогового консультирования или при выполнении экспертных работ по заданию государственных органов с целью полноты охвата вопросов консультирования и этапов работ по анализу применяемой налогоплательщиком системы учета в целях налогообложения необходимо опирать- ся на разработанные экспертные процедуры, результатами которых является оценка качественных аспектов объектов экспертизы или исследования при его проведении в порядке классификации их качественных характеристик (таблица 1, составлено автором) [4].

В процессе оценки информации при оказании консультационной услуги в области налогообложения или проведения экспертного исследования в процессуальном поле по вопросам исчисления и исполнения обязательств перед бюджетом по налогу эксперт опирается на нор-

\section{Таблица 1. Экспертные процедуры для оценки качественных аспектов искажения}

\begin{tabular}{|c|c|}
\hline Качественный аспект & Цели экспертной процедуры \\
\hline 1 & 2 \\
\hline Существование & $\begin{array}{l}\text { Оценить отражение всех элементов, составляющих объект налогообложения, } \\
\text { (например, доходы и расходы), порядок их формирования на основании } \\
\text { первичных документов и отражения в налоговом учете. } \\
\text { Оценить реальность существования объектов учета и их отношение к прове- } \\
\text { ряемому отчетному периоду. В случае нереальности (фиктивности) учетного } \\
\text { объекта оценить его влияние на величину налогооблагаемой базы и сумму } \\
\text { налога, исчисленную налогоплательщиком. }\end{array}$ \\
\hline Достоверность & $\begin{array}{l}\text { Оценить получение доходов и наличие (формирование) расходов (или выче- } \\
\text { тов) налогоплательщика подтверждено из внешних источников (от третьих } \\
\text { лиц). }\end{array}$ \\
\hline Полнота & $\begin{array}{l}\text { Оценить полноту отражения элементов объекта налогообложения в налого- } \\
\text { вом учете. }\end{array}$ \\
\hline Оценка (измерение) & $\begin{array}{l}\text { Оценить правильность оценки элементов объекта налогообложения, пра- } \\
\text { вильность исчисления сумм каждого вида и итоговых показателей по груп- } \\
\text { пам (классам) и в общем объеме, правдивость отражения совокупной суммы } \\
\text { налогоплательщиком в составе объекта налогообложения. }\end{array}$ \\
\hline Классификация & $\begin{array}{l}\text { Оценить классификацию элементов налогообложения по соответствующим } \\
\text { группам в порядке, предусмотренном НК РФ. }\end{array}$ \\
\hline $\begin{array}{l}\text { Формирование объекта } \\
\text { налогообложения }\end{array}$ & $\begin{array}{l}\text { При формировании объекта налогообложения оценить примененное } \\
\text { соотношение доходов и расходов их относимость, к налоговому периоду, } \\
\text { порядок организации ведения раздельного налогового учета в соответствии } \\
\text { с правилами, установленными НК РФ. }\end{array}$ \\
\hline $\begin{array}{l}\text { Представление в налоговом } \\
\text { учете }\end{array}$ & $\begin{array}{l}\text { Оценить информационную базу, на которой строится налоговый учет } \\
\text { (на базе бухгалтерского учета или в отдельной базе налогового учета), осу- } \\
\text { ществляется формирование аналитических налоговых регистров и состав- } \\
\text { ление расчета налога в соответствии с требованиями НК РФ и принятой } \\
\text { учетной политикой, применяемой в целях налогообложения налогоплатель- } \\
\text { щиком. }\end{array}$ \\
\hline $\begin{array}{l}\text { Представление в налоговой } \\
\text { отчетности }\end{array}$ & $\begin{array}{l}\text { Провести экспертный анализ порядка сформированных налогоплатель- } \\
\text { щиком налоговых деклараций в соответствии с данными налогового учета } \\
\text { налогоплательщика и с данными расчета налога, в соответствии с принятой } \\
\text { учетной политикой, применяемой в целях налогообложения налогоплатель- } \\
\text { щиком. }\end{array}$ \\
\hline $\begin{array}{l}\text { Представление и раскрытие } \\
\text { в бухгалтерской (финансовой) } \\
\text { отчетности }\end{array}$ & $\begin{array}{l}\text { Проверить начисленное налогоплательщиком обязательство по уплате и } \\
\text { возврату налогов, а также расход по налогу на прибыль. Определить пра- } \\
\text { вильность классификации объекта учета и раскрытия информации об объек- } \\
\text { те в финансовой отчетности с достаточной степенью детализации. }\end{array}$ \\
\hline Исполнение обязательств & $\begin{array}{l}\text { Эксперт определяет своевременность отражения начисленного налога, под- } \\
\text { лежащего уплате в бюджет, в составе задолженности в бухгалтерском учете } \\
\text { (в составе финансовой отчетности) и полноты перечисления суммы налога } \\
\text { в бюджет, а также наличие финансовых ресурсов у предприятия на дату, } \\
\text { установленную в НК РФ, исполнения обязательства по налогу. }\end{array}$ \\
\hline
\end{tabular}


мативные требования налогового законодательства РФ, положения нормативных актов РФ по бухгалтерскому учету, принимает во внимание позиции судебных органов, изложенные в Постановлениях и Информационные сообщения ВАС РФ и ВС РФ. Для ориентира при оказании услуги налоговый консультант (или эксперт) может разработать координаты источников информации или подходящий алгоритм с адресами источников информации, который нужно актуализировать с определенной периодичностью.

Фактически государственные рамки для профессиональной деятельности установлены только для аудиторов в ФЗ «Об аудиторской деятельности», который подразумевает контроль качества работы аудиторских организаций, независимость аудитора и другие требования [5]. Названный закон также закрепляет понятие аудиторской тайны, которая обеспечивает конфиденциальность и неразглашение информации о финансово-хозяйственной деятельности клиента без его согласия. Понятие аудиторской тайны, как и налоговой тайны, которую составляют полученные сведения и данные налоговыми органами о налогоплательщики (ст. 102 НК РФ) [6], не включают в себя положения по соблюдению современных протоколов по информационной безопасности в процессе сбора и обработки данных. К таким протоколам относятся: сознательное ограничение пользования смартфонами при работе с документами, содержащими коммерческую тайну организаций; отключение антивирусной защиты; исключение использования чужих паролей и средств идентификации; запрет копирование данных организации на цифровые носители без разрешения уполномоченного лица организации и т.д.

Конфиденциальность является важным принципом деятельности налогового консультанта, наряду с такими принципами как: соблюдение законодательства РФ, высокий уровень квалификации и опыта консультанта, его добросовестность, честность, объективность и независимость мнения от любых обстоятельств. Соблюдение названных принципов качество работы консультанта прежде всего повышает доверие к работе налогового эксперта. При анализе оказанной услуги клиентом оценивается как организация оказания услуги компанией, так и личный вклад и действия непосредственного налогового консультанта. Личные качества консультанта и его профессионализм относятся к обобщенному понятию интеллектуального капитала сотрудника организации.

Здесь отметим, что привлечение налоговых консультантов в качестве специалистов или экспертов в судебном или следственном процессе в соответствии, с процессуальным законодательством, будет требовать независимости деятельности консультанта от субъекта, который является налогоплательщиком, налоговый учет, порядок исчисления и уплаты налогов которого подлежит оценке или экспертному исследованию.

Сложным вопросом является оценка компетентности экспертов в области налогообложения, как элемента интеллектуального капитала. Интеллектуальный капитал, накопленный специалистом, может терять свою актуальность, так как информация со временем способна устаревать. Налоговое законодательство в России постоянно обновляется, соответственно налоговым консультантам экспертам в области налогообложения следует регулярно подтверждать свою компетенцию, однако законодательно это не закреплено.

Несмотря на то, что на официальном сайте Палаты налоговый консультантов ведется общественное обсуждение профессионального стандарта «Консультант по налогам и сборам» [7], по нашему мнению, недооцененным со стороны профессионального сообщества является необходимость реализации правил оценки квалификаций и компетенций, в соответствии с Федеральным законом от 03.07.2016 N 238-Ф3 «О независимой оценке квалификации». Однако данный вопрос сложный и требует развития в отдельной публикации, рамки данной статьи не позволяют углубиться в данном направлении.

Подтверждение знаний и умений присутствует в профессиональной деятельности аудиторов, которые обязаны согласно ФЗ «Об аудиторской деятельности» проходить квалификационные экзамены для получения аттестата аудитора. Экзамен проводится в формате компьютерного тестирования, где блок вопросов посвящен налоговому законодательству РФ. Мониторинг успешности прохождения тестирования претендентами представлен на рисунке 1.

Средний процент прохождения экзамена за период с 2015 г. по 2019 г. включительно - 26\%. В 2019 г. экзамен сдали 32\% трестирующихся из общего числа 1629 человек, в 2018 г. из 1111 человек - 31\%, в 2017 г. из 2190 человек - 20\%, в 


\section{Анализ результатов сдачи компьтерного тестирования на квалификационном экзамене для получения аттестата аудитора}

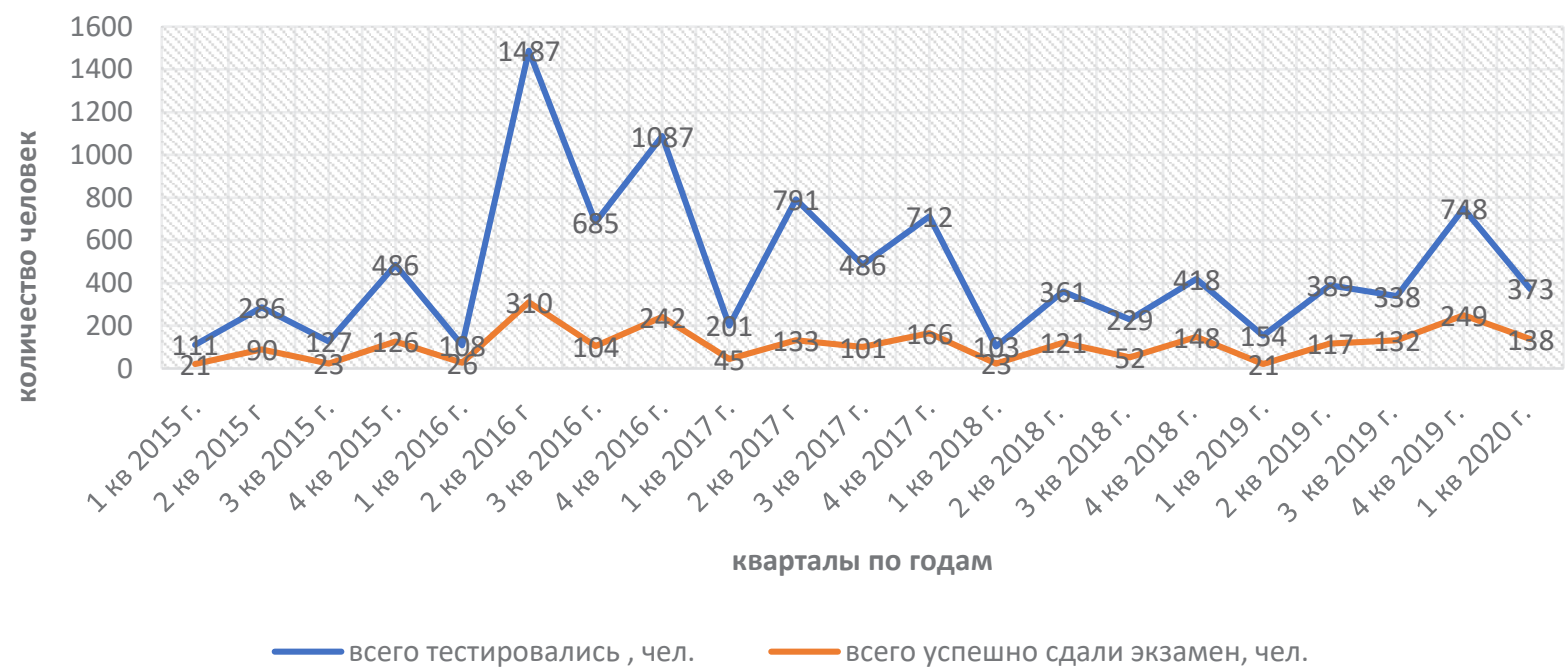
Puc. 2. Анализ результатов сдачи компьютерного тестирования на квалификационном экзамене для получения квалификационного аттестата аудитора*
* Составлено по данным АНО «Единой аттестационной комиссии» [8]

2016 при наибольшем количестве претендентов в 3367 человек экзамен сдали только 20\%, а в 2015 г. из 1010 человек - 26\%.

Экзамены и обучение предусмотрены в профессиональных сообществах налоговых консультантов, к ним относятся организации: Палата налоговых консультантов (ПНК), Институт профессиональных бухгалтеров, Ассоциации консультантов по экономике и управлению. Палата налоговых консультантов на своем Официальном сайте содержит реестр налоговых консультантов, в котором содержится информация о 132 членах, что ничтожно мало для такого государства как Российская Федерация [7]. Однако, данные о результатах экзаменов, данные о повышении квалификации в реестре членов в данных организациях, причины исключенных из реестров членов не публикуются в открытых источниках.

Палата налоговых консультантов проводит экзамен по окончанию обучения новых претендентов, успешная сдача позволяет получить квалификационный аттестат ПНК и параллельно получить членство в Палате [7]. В ПНК разработан внутренний документ «Нормы профессиональный этики ПНК», в котором установлены основы нравственного и морального облика, необходимых в деятельности консультанта [7]. За основы взяты элементы человеческого капитала налоговых консультантов: основные принципы их деятельности, деловые и личные качества индивида, активное участие в работе профессионального сообщества.

ИПБ России на основании внутренний документов («Положение о тестировании», «Положение о выдаче аттестатов ИПБ России») проводит тестирование с целью получения аттестата профессионального налогового консультанта после освоения претендентами программы подготовки специалистов. Члены ИПБ России могут пройти тестирование без прохождения обучения по курсам области налогообложения [9]. АКЭУ проводит сертификацию консультантов и юридических лиц - консалтинговых организаций, которая дает членство в сообществе. Члены АКЭУ наделены полномочиями по организации региональных представительств, привлекаются к консультациям объединения и включаются в Реестр Европейского банка реконструкции и развития, что позволяет выполнять проекты по его заявкам [10].

Анализ деятельности профессиональных объединений в сфере налоговых консультаций показывает, что подтверждение уровня квалификации - эффективный инструмент для отбора специалистов. Однако в России нет единой 
прозрачной и структурированной системы позволяющей производить оценку квалификации в данной сфере. В процессе развития независимой оценки квалификации в РФ, в данный момент в разработке находится стандарт «Консультант по налогам и сборам», ответственным разработчиком которого является ПНК; на утверждении Министерством труда и социальной защиты РФ находится профессиональные стандарт «Эксперт по налоговым спорам». В ТК РФ установлено, что целесообразность направления на экзамен по независимой оценке квалификации для нужд организации определяется непосредственно работодателем с учетом мнения выборного органа первичной профсоюзной организации при его наличии (ст. 196 ТК РФ).

Консалтинговые фирмы прибегают к процедуре оценке квалификации на добровольной основе, проводя ее либо по установленным внутри организации положениям, либо обращаясь к услугам профессиональных сообществ. Аттестаты налоговых консультантов в профессиональных объединениях могут получить и внутренние специалисты в том числе по собственной инициативе. Каждое профессиональное сообщество предлагает свои методики оценки квалификации специалистов, наборы оценочных средств, поэтому конечный потребитель при выборе налогового консультанта опирается прежде всего на известность субъекта консультирования на рынке, на рейтинг бренда предприятия, оказывающей услуги в области налогообложения, и на деловую репутацию индивидуальных налоговых консультантов. Необязательность квалификационного отбора негативно отражается на имидже понятия налогового консультанта, так как на рынок попадают специалисты с низкой компетенцией, отсутствием достаточного опыта в работе и несоблюдающие этические требования к профессии.

Другой причиной низких темпов развития консультационных услуг является отсутствие сформированной в обществе культуры налогового консультирования. Профессиональные сообщества не имеют влияние на всех участников рынка консультирования, в связи с чем нет единого механизма регулирования деятельности налоговых консультантов и непосредственно самих объединений, это предусмотрено только аудиторской деятельностью. Организации - клиенты не хотят привлекать внимание к своей деятельности, а также не хотят затрачивать денежные средства на услугу, при отсутствии точной уверенности в решении конкретной ситуации, поэтому до момента реальной угрозы налоговой ответственности пытаются решить налоговые споры самостоятельно.

В современном подходе ФНС к решению налоговых споров большое внимание уделяется досудебному регулированию споров, что открывает для налоговых консультантов хорошие перспективы по привлечению потенциальных клиентов, так как профессиональные консультанты по идее обладают достаточным опытом и компетенцией для данной работы. Следующие статистические данные показывают возможное поле деятельности для налоговых консультантов, которые оказывают услуги представительства налогоплательщиков или иным образом участвуют на стадии налоговых споров. Количество рассмотренных жалоб по итогам 2019 г. от налогоплательщиков составило 22, 7 тыс. жалоб, по сравнению с 2018 годом данный показатель стал ниже на 6,2\%. Число рассмотренных жалоб налоговыми органами по результатам камеральных и выездных налоговых проверок в 2019 г. снизилось на 25,5\% по сравнению с предыдущим годом. Показатель по судебному делопроизводству по обжалованию результатов мероприятий налогового контроля снизился в 2019 г. на 24\%, но по-прежнему сохраняется перевес дел, решение по которым было в пользу налоговых органов $-72,5 \%$, что в эквиваленте поступивших денежных средств в бюджет составило 103,1 млрд. руб. [2].

Подводя итоги, стоит отметить, что внедрение единого подхода к внутреннему и к внешнему механизмам контроля деятельности налоговых консультантов, а также судебных налоговых экспертов в области налогообложения, тщательная проработка процедуры оценки качества специалистов, с учетом существующих подходов профессиональных объединений в сфере налогового консультирования; разработка методики оказания услуг, отвечающая современным требованиям рынка и положениям цифровой экономики, позволят повысить доверие потребителей и продвинуть участников рынка, отвечающим стандартам качества, а также этическим требованиям профессии. 


\section{Библиографический список}

1. «Паспорт национального проекта «Национальная программа «Цифровая экономика Российской Федерации» (утв. президиумом Совета при Президенте РФ по стратегическому развитию и национальным проектам, протокол от 04.06.2019 N 7).

2. ИФНС России [Электронный ресурс]: официальный сайт ИФНС России - Москва, 2005-2020.- Режим доступа: https://www.nalog.ru/rn77/related_activities/statistics_and_analytics/effectiveness/ (дата обращения: 28.04.2020)

3. Махмудова И.Н., От благонадежности к лояльности персонала для обеспечения кадровой безопасности организации / И.Н. Махмудова, Ю.А. Криворучко / Кадровик. - 2019. - № 7. - С. 93-100

4. Князева Н.В. Диссертация на соискание ученой степени кандидата юридических наук «Экспертиза в налоговом контроле и при разрешении налоговых споров: правовые и институциональные особенности», защита состоялась 14.02.2019, Официальный сайт совместного диссертационного совета 999.067.02 Российского университета дружбы народов (РУДН) и РПА Минюста России URL: http://dissovet.rudn.ru/web-local/ prep/rj/index.php?id=43\&mod=dis \&dis_id=2334

5. Федеральный закон от 30.12.2008 N 307-ФЗ (ред. от 26.11.2019) «Об аудиторской деятельности» Режим доступа: http://www.consultant.ru/document/cons_doc_LAW_83311/

6. «Налоговый кодекс Российской Федерации (часть первая)» от 31.07.1998 N 146-ФЗ (ред. от 29.09.2019, с изм. от 31.10.2019) (с изм. и доп., вступ. в силу с 29.10.2019) Режим доступа: http://www.consultant.ru/document/ cons_doc_LAW_19671/

7. Союз по организации деятельности консультантов по налогам и сборам «Палата налоговых консультантов» [Электронный ресурс]: Союз «ПНК».- Москва, 2019.- Режим доступа: www.palata-nk.ru (дата обращения: 15.03.2020)

8. АНО «Единая аттестационная комиссия» [Электронный ресурс]: официальный сайт АНО «ЕАК».- Москва, 2010-2020.- Режим доступа: https://eak-rus.ru/rezultaty_ekzamenov/obobwennyj_analiz_rezul_tatov_ kvalifikacionnyh_e_kzamenov (дата обращения: 02.06.2020)

9. НП «Институт профессиональных бухгалтеров России» [Электронный ресурс]: НП «ИПБ России» - Москва, 2000-2020.- Режим доступа: https://www.ipbr.org/ (дата обращения: 01.06.2020)

10. «Ассоциация консультантов по экономике и управлению» [Электронный ресурс]: «АКЕУ» - Москва, 2020.Режим доступа: http://akeu.ru/about/certification/ (дата обращения: 29.05.2020) 